\title{
The Development and Application of a Wetland Ecosystem Evaluation Model
}

\author{
Han-Shen Chen ${ }^{1,2}$ \\ ${ }^{1}$ School of Health Diet and Industry Management, Chung Shan Medical University, Taiwan \\ ${ }^{2}$ Dept. of Medical Management, Chung Shan Medical University Hospital, Taiwan
}

\begin{abstract}
This study applied emergy ecological footprints (EEF) to investigate a national coastal wetland in Taiwan-Gaomei Wetlands. A wetland ecosystem evaluation model was used to quantify the EEFs and emergy ecological carrying capacity (EECC) of Gaomei Wetlands between 2007 and 2013 to examine the current environmental situation of the area. In addition, we employed the grey model to predict the EEF, EECC, and ecological safety of Gaomei Wetlands. Based on the research results, we provided a reference for environmental policy execution and planning, as well as strategies and suggestions for the sustainable development of Gaomei Wetlands. The results indicated the following: The prediction results of the grey model showed that the 2014-2023 ecological carrying capacities of Gaomei Wetlands decreased and the per capita EFs increased extensively, which enlarged the ecological deficit and elevated the EFI. In addition, the level of 2014-2023 ecological security is higher than that of 7 years ago and is expected to reach the Grade 2 intermediate level in 2021, indicating that Gaomei Wetlands is gradually becoming ecologically unsustainable.
\end{abstract}

Keywords- wetlands; ecosystem; emergy ecological footprint; ecological security; grey model.

\section{INTRODUCTION}

Based on the Millennium Ecosystem Assessment of the United Nations regarding global ecosystems, wetlands are the most adversely damaged, in which biodiversity is severely threatened. The continuous loss and degradation of wetlands will gradually weaken the service function of ecosystems, thereby decreasing the well-being of people [1]. In the past decade, approximately a loss of 30\%-50\% wetlands worldwide was incurred by climate change and human damage [2-3]. In fact, wetlands are extremely crucial natural resources that provide functions such as seashore protection, flood regulation, underground water replenishment, fish and shellfish propagation, water purification, climate adjustment, and ecotourism destination development [4-8].

In 2007, Gaomei Wetlands, the research site used in this study, has been designated as a national wetland in Taiwan. In recent years, Gaomei Wetlands has become a crucial water bird habitat and a prominent bird-watching spot. However, human disturbances such as the construction of the Provincial Highway 61 and wetland park development have caused rapid losses of sand bars and mangroves and a decline in biodiversity. This consequently endangered the ecological environment. Typically, during the development of natural resources, the sustainable development of ecology, economy, and society and the mitigation of recreational impact must be simultanesouly considered. Thus, based on this notion, this study investigated how the sustainable management and development of wetlands can be ensured to facilitate the conservation of the environmental ecosystem, thereby realizing critical environmental protection topics such as biodiversity and climate changes.

In summation, this study applied EEF to construct an evaluation model that is applicable for assessing the environmental carrying capacity of wetlands, to quantify the 2007-2013 EEFs and EECC of Gaomei Wetlands. In addition, the grey prediction method was used to predict the EEF, EECC, and ecological security of Gaomei Wetlands. The results can serve as references for the execution and planning of environmental policies. Lastly, based on the results, we proposed strategies and suggestions for the sustainable development of Gaomei Wetlands.

\section{METHOD}

\section{A. The calculation and analysis of EEF and EECC}

The basic concept of ecological footprint involves applying the EA theory to convert the actual consumptions and resources of six biologically productive lands (fossil fuel lands, croplands, meadows, forest lands, building lands, and waters) into a quantifiable standard-emergy. Furthermore, by introducing the concept of emergy density (the amount of emergy based on the unit area of all renewable resources), emergy is converted to an area concept that is relatively more comprehensible.

The calculation of regional EEF is divided into two parts: biological and energy resources. Biological resources include agricultural, forestry, husbandry, and fishery products, all of which correspond to the four biologically productive lands of croplands, forest lands, meadows, and waters. Energy resources include coal, crude oil, natural gas, and electricity, where electricity corresponds to building lands and the remaining energy sources correspond to fossil fuel lands. Subsequently, calculating the sum of the amount of emergy that corresponds to the actual consumption amount in biologically productive lands yields the amount of emergy consumed per capita $\left(c_{i}\right)$, which is then divided by $\left(P_{1}\right)$ to attain the per capita EEF (ef). In this study, Eq. (2.1) is expressed as follows: 


$$
\text { ef }=\sum_{i=1}^{n} a_{i}=\sum_{i=1}^{n} c_{i} / P_{1}
$$

where $i$ represents types of consumed resource; ef represents per capita EEF; $a_{i}$ represents the area corresponding to the amount of $i^{\text {th }}$ resource consumed per capita; $c_{i}$ represents the amount of per capita emergy consumed from the $i^{\text {th }}$ resource (unit is sej); $P_{1}$ represents regional emergy density; and $P_{1}=$ total acquired regional emergy/regional area (the unit is $s e j / \mathrm{m}^{2}$ ).

EECC is the ratio of the emergy of all renewable resources in the research site to the mean global emergy density. When calculating regional EECC, the emergy amount of renewable resources that can be attained by regional population should be calculated first. The renewable resources include solar radiation energy, wind energy, rain chemical energy, rain geopotential, and the rotational energy of the earth. In addition, to prevent repeated calculation, the maximum value is used as the total emergy acquired in a region to obtain the amount of emergy per capita of resource supply $(e)$, which is then divided by emergy density $\left(P_{2}\right)$ to attain the per capita emergy ecological carrying capacity $(e c)$. The equation is expressed as follows:

$$
e c=e / P_{2}
$$

where $e c$ represents per capita emergy ecological carrying capacity; $e$ represents the emergy per capita of resource supply; and $P_{2}$ represents global emergy density, with a unit identical to that of $P_{1}$

The equation for $P_{2}$ is expressed as follows:

$P_{2}=$ total emergy of the earth/the area of the earth =

$$
\frac{1.583 \times 10^{25}}{5.1 \times 10^{14}}=3.1 \times 10^{10} \mathrm{sej} / \mathrm{m}^{2} \mathrm{a}
$$
sej/a

The emergy basis of the earth's biosphere is $1.583 \times 10^{25}$

\section{B. The dynamic analysis and evaluation of ecological security}

In this study, because the EF per unit area can objectively reflect the pressure of an ecological environment, we adopted the Ecological footprint pressure index (EFI) to measure regional ecological security. Theoretically, an intense ecological pressure signifies low level of ecological security.

The EFI is defined as the ratio of per capita EEF ( $e f^{\prime}$ ) to emergy ecological carrying capacity of renewable resources. The EFI is the carrying capacity of ecological environments and the equation is expressed as follows:

$$
\mathrm{EFI}=\text { ef } 1 / e c
$$

where EFI represents ecological footprint pressure index; $e f$ ' represents per capita EEF of renewable resources; and $e c$ represents per capita EECC.

EFI equal to 1 represents supply and demand equilibrium and that the ecosystem is in the threshold of sustainable development. An EFI smaller than 1 represents that the EECC is greater than the EEF, meaning that the ecosystem loading is in a normal, sustainable state. An EFI greater than 1 represents that the EEF is greater than the EECC, which means that human consumption has exceeded the ecological carrying capacity and the ecosystem is overloaded, deviating from a state of sustainability.

This study applied per capita EECC and per capita EEF to calculate the 2007-2013 EFIs of Gaomei Wetlands (Table 1). The results showed that the EFI of Gaomei Wetlands increased from 1.08 in 2007 to 2.14 in 2013, which indicated that the ecological environment is constantly subjected to stress to a point that the ecological security is threatened.

TABLE I. THE 2007-2013 EFI AND ES OF GAOMEI WETLANDS

\begin{tabular}{|c|c|c|c|c|c|c|c|}
\hline Year & 2007 & 2008 & 2009 & 2010 & 2011 & 2012 & 2013 \\
\hline EFI & 1.08 & 1.34 & 1.36 & 1.43 & 1.80 & 1.97 & 2.14 \\
\hline ES level & 2 & 2 & 2 & 2 & 2 & 2 & 2 \\
\hline $\begin{array}{c}\text { ES } \\
\text { evaluation }\end{array}$ & Safe & Safe & Safe & Safe & Safe & Safe & Safe \\
\hline
\end{tabular}

\section{III.RESULTS AND DISCUSSION}

Based on the fundamental data of the grey prediction model, we predicted the 2014-2023 per capita EEFs and per capita EECCs of Gaomei Wetlands (Table 2). Although the 2014-2023 per capita EECCs of Gaomei Wetlands increased slightly, the 2019-2023 capacities decreased. In addition, the 2014-2023 per capita EEFs grew substantially. This is expected to enlarge the regional per capita ecological deficit and render the development of the entire region unsustainable, thereby further endangering the ecological environment of the region.

Based on the prediction results for 2014-2023, the 2014-2023 per capita ecological deficit and surplus values can be attained (Table 2). The results showed that the 2014-2023 ecological deficits of Gaomei Wetlands gradually increased. In the future development of Gaomei Wetlands, because EF and per capita demand continually increase annually, while natural supplies continue to decrease, the per capita ecological deficit in 2023 is anticipated to be $-23.03 \mathrm{hm}^{2} /$ cap. This means that human demand will exceed the load capacity of nature considerably, thereby causing the ecological environment to deteriorate. In addition, In 2014-2023, although the ecological security level of Gaomei Wetlands satisfied the safety standard, the EFI increased, which will induce a rapid deterioration of the ecological environment.

By using EFI-related data and integrating these data with the ecological security standards, the results of the 2014-2023 ecological security can be obtained (Table 2). In 2017, Gaomei Wetlands is expected to reach the Grade 2 intermediate level, and the early-warning level will increase rapidly over time. The reason might be that tourist demands for resources and services (e.g., bus service, road constructions, and waste production) increase as the number of people increases. Therefore, we suggest that the managers of Gaomei Wetlands continue to track tourists' recreational demands and tourists' usage conditions of 
recreational facilities and resources by using satisfaction surveys. Therefore, a basis for revising EEF calculation methods and for precisely evaluating the capacity for tourist load in Gaomei Wetlands can be attained.

TABle II. The EVAluation AND EARLy WARning State of ES Over The Years

\begin{tabular}{|c|c|c|c|c|c|c|c|c|}
\hline \multirow{2}{*}{ Year } & \multirow{2}{*}{\multicolumn{2}{|c|}{ Per capita EECC Per capita EEF }} & \multirow{2}{*}{$\begin{array}{c}\text { Ecological } \\
\text { deficit/surplus }\end{array}$} & \multicolumn{3}{|c|}{ EFI } & \multicolumn{2}{|c|}{ ES early warning state } \\
\hline & & & & Index & Grade & Safety Status & Level & Satus \\
\hline 2014 & 3.92 & 9.24 & -5.32 & 2.36 & 2 & Safe & 1 & Mild \\
\hline 2015 & 3.95 & 10.40 & -6.45 & 2.63 & 2 & Safe & 1 & Mild \\
\hline 2016 & 3.99 & 11.71 & -7.72 & 2.93 & 2 & Safe & 1 & Mild \\
\hline 2017 & 4.03 & 13.18 & -9.15 & 3.27 & 2 & Safe & 1 & Mild \\
\hline 2018 & 4.07 & 14.83 & -10.76 & 3.64 & 2 & Safe & 1 & Mild \\
\hline 2019 & 4.02 & 16.70 & -12.68 & 4.15 & 2 & Safe & 1 & Mild \\
\hline 2020 & 3.96 & 18.79 & -14.83 & 4.74 & 2 & Safe & 1 & Mild \\
\hline 2021 & 3.93 & 21.15 & -17.22 & 5.38 & 2 & Safe & 2 & Intermediary \\
\hline 2022 & 3.87 & 23.80 & -19.93 & 6.15 & 2 & Safe & 2 & Intermediary \\
\hline 2023 & 3.76 & 26.79 & -23.03 & 7.13 & 2 & Safe & 2 & Intermediary \\
\hline
\end{tabular}

\section{IV.CONCLUSION}

The grey model was adopted to predict the 2014-2023 EEFs and ecological carrying capacities of Gaomei Wetlands. Next, ecological deficit values and EFIs were calculated to predict the ecological security trend and relevant early warning status. The results showed that the 2014-2023 ecological carrying capacities of Gaomei Wetlands decreased, the regional per capita EF increased considerably, and the ecological deficit and EFI increased. The results of ecological security evaluation revealed that between 2014 and 2023, the ecological security level of Gaomei Wetlands met the safety condition. However, combined with the EFIs, the ecological security status exhibited a declining trend, which is expected to cause the ecological environment to deteriorate. The ecological security level during 2014-2023 was greater than that of 7 years ago and is anticipated to reach the Grade 2 intermediate level in 2021. Moreover, the early warning level will also increase rapidly over the years.

\section{ACKNOWLEDGEMENTS}

We thank the National Science Council of Taiwan for providing financial support for this research project under grant number NSC 102-2410-H-040-010.

\section{REFERENCES}

[1] Bridgewater, P. B.Wetscapes, a new concept for the Ramsar, CBD and CMS Conventions.First SWS Asia Chapter's 2008 Asian Wetland Convention Keynote Speech, 2008.

[2] Valiela, I. \& Fox, S. E. Managing Coastal Wetlands. Science, 319, 321-323, 2008.

[3] Miththapala, S. Mangroves: Coastal Ecosystems Series. Colombo, Sri Lanka: Ecosystems and Livelihoods Group Asia, IUCN, 2008.

[4] Zedler, J. B. \& Kercher, S. Wetland Resources: Status, Trends, Ecosystem Services, and Restorability. Annual Review of Environment and Resources, 30, 39-74, 2005.

[5] Yang, W., Chang, J., Xu, B., Peng, C.\& Ge, Y. Ecosystem service value assessment for constructed wetlands: A case study in Hangzhou, China. Ecological Economics, 68(1-2), 116-125, 2008.

[6] Fletcher, S., Kawabe, M. \& Rewhorn, S. Wetland conservation and sustainable coastal governance in Japan and England. Marine Pollution Bulletin, 62(5), 956-962, 2011.

[7] Feng, M., Liu, S., Euliss Jr, N. H., Young, C. \& Mushet, D. M. Prototyping an online wetland ecosystem services model using open model sharing standards. Environmental Modelling \& Software, 26(4), 458-468, 2011.

[8] Su, C. H., Fu, B. J., He, C. S. \& Lu, Y. H. Variation of ecosystem services and human activities: A case study in the Yanhe Watershed of China. Acta Oecologica, 44, 46-57, 2012. 